\title{
Metastatic Infiltrating Bladder Urothelial Carcinoma, Nested Variant
}

National Cancer Institute

\section{Source}

National Cancer Institute. Metastatic Infiltrating Bladder Urothelial Carcinoma, Nested

Variant. NCI Thesaurus. Code C157770.

Bladder nested variant urothelial carcinoma that has spread to another anatomical site. 